Decisicins an DesIGnS, Inc.
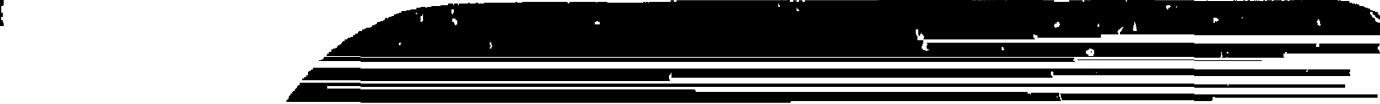

(1)
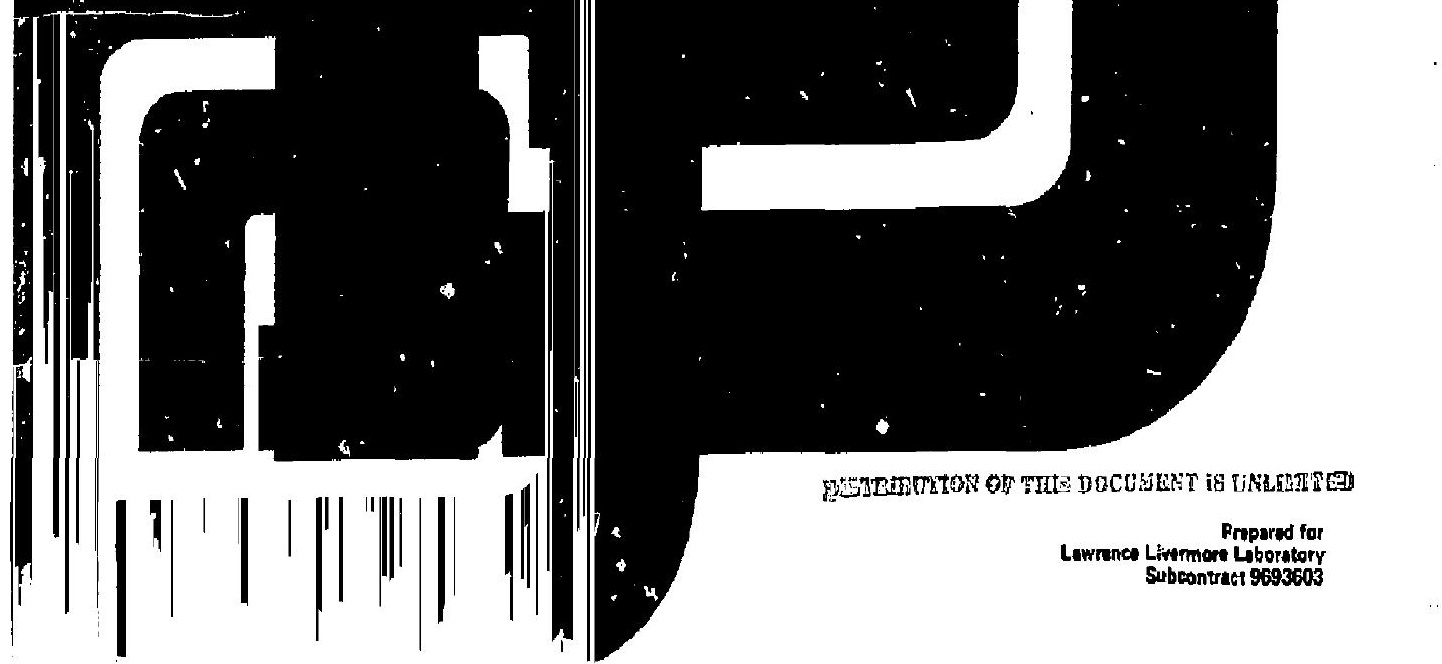


\title{
TOWARD ANALYTIC AIDS FOR STANDARD SETTING IN NUCLEAR REGULATION
}

\author{
by
}

Rex V. Brown. Michael F. O'Connor and Camei on R. Peterson

Prepared for

Lawrence Livermore Laboratory

Subcontract 9693603

May 1979

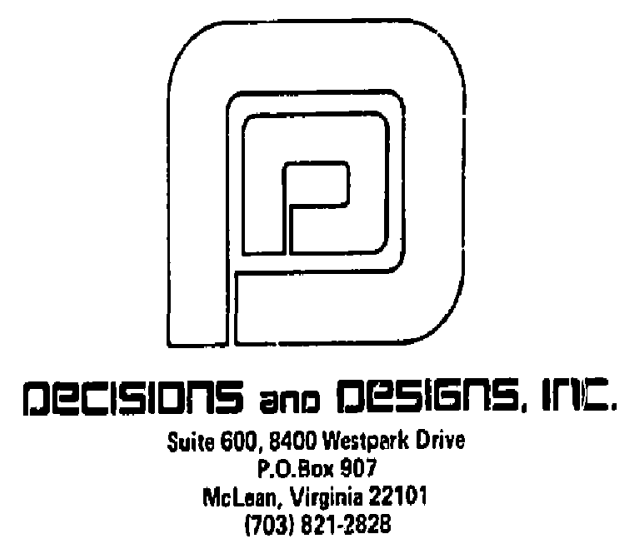

Tis nemat in motict

xoram on mork

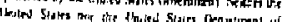

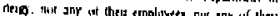

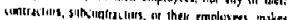

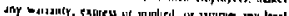

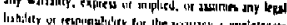

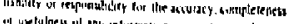

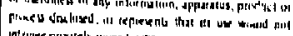

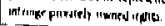

P.O.Box 907
McLean, Virginia 22101

(703) 821-2828 
The U. S. Nuclear Regulatory Commission (NRC) promulgates standards for nuclear reprocessing and other facilities to safeguard against the diversion of nuclear material. Such standards are normally expressed in operational terms, for example, requiring that certain unambigious procedures be observed so that compliance can be readily verified. However, the writing and implementation of the standards can be enhanced by identifying performance criteria lor guidelines) which the regulated facilities should satisfy.

Illustrative performance criteria or guidelines might be as follows:

- in any given year the probability of 5 formula kilograms of plutonium being diverted from a given facility should be no more than .01;

- the probability of an attempt of a given kind being successful should not exceed .05 ;

- the expected societal risk for diversion attempts, if any, should be less than .03 (on a scale where $l$ is a specified bad outcome and 0 is the best outcome, i.e. no diversionary activity at all).

Higher order performance measures going beyond societal risk might include impact on energy cost and supply to the public, operator profitability and convenience, and administrative convenience to the regulating agency.

At whatever performance Ievel the actual standards are set and regulations written, all higher orders of performance 
levels will neeo to be taken into account, explicitly or implicitly, in order to evaluate alternative standards. Furthermore, lower order performance measures will probably also be considered, at least by facility operators, in the course of determining how the higher order performance measures can be satisfied.

Two broad tasks have been directed toward establishing performance criteria for standard settings. The first is general-purpose modelling to explore the probable societal conseguences of different facilities. The second involves analysis specific to a particular performance criterion option, for example, setting a minimum acceptable level of risk defined in terms of probability of attempt, probability of success, and consequence if successful. The two tasks interact in the sense that the second draws on findings from the first, and the first is designed with a view to answerinc questions of the second kind. A third task, stemming from the second, is to adapt any analytic aid to the practical needs of the decision-making process at NRC.

The first task, general-purpose modelling, has been partially covered in a previous report by Decisions and Designs, Incorporated (DDI) (Brown and Feuerwerger 1978). The probable societal risk consequences of a facility with given safeguards was modelled in a summary macro-model. The inodel was developed and implemented on a portable interactive computer for the Lawrence Livermore Laboratory (LLL) as part of a study of the effectiveness of Materials Control and Accounting (MC $\AA A$ ) systems for nuclear reprocessing plants. The purpose of the study is to help the Nuclear Regulatory commission evaluate and implement regulations bearing on MCSA Systems and to help LLL organize and communicate its more detailed analyses of the same issues. 
Based on judgments developed in the LLL study, the model displays, for a given facility and $\mathrm{Mr} \overline{\mathrm{X}}$ system, both the probable outcome--in terms of detection of adversiry attempts, plutonium stolen, plant deaths, damage, and the like--and the aggregated measure of utility for such consequences. Comparable displays are available conditional on differing stages in a theft attempt sequence, for example, on a particular type of attempt or on a detected but not interrupted attempt. The inputs to the model are summary judgments with respect to the probability of differing attempts, probable responses to the attempts from the MC\&A and security systems, and trade-off judgments on the relative utilities of outcomes.

A basic version of the macro-model was developed on the basis of judgmental inputs supplied by $D$. Ivan sacks of LIL and has been presented with graphic displays to LLL and IRC staff. It was proposed to interface the macro-model with the detailed LIL assessment, to develop alternate inputs, and to adapt the model and its displays to LLL's and NRC's specific needs. The primary functions of the marco-model are to facilitate communication of the results of: LILI's detailed assessment, to focus further effort within that study, and to provide NRC with a compact operational tool to regulate, license, police, and design facilities.

This report emphasizes work on the second task, analysis specific to a particular performance criterion option, for example, that of determining a threshold or optimal probability of success for any attempt (taking into account relevant costs). The main purpose of the work is tu provide a framework for the evaluation of such options that organizes the necessary components in a way that provides for meaningful 
assessments with respect to required inputs. The approach, based on the decision-analytic technique known as multiattribute utility assessment, begins with a highly simplified example and then proceeds to a more general overall framework.

Task three has proceeded only to the point of identifying relevant aspects of NRC's decision-making process. The report concludes with recommended directions for Iurther research. 


\section{CONTENTS}

Page

SUMMARY

ii

FIGURES

viii

PREFACE

ix

1.0 PROBLEM FORMULATION 1

1.1 Objective 1

1.2 problem Setting I

1.2.1 What is to be reguiated 1

1.2 .2 Current status 2

1.2.3 Organization of NRC decision
process

1.3 Regulatory Options 4

1.3.1 General 4

1.3.1.1 Level of generality 5

1.3.1.2 Multiple versus
composite thresholds $\quad 7$

1.3.2 Complexities of possible realistic

options 11

1.3.3 Specific options to be examined 12

1.4 Specification of Aids to be Developed 13

1.4.1 NRC tasks to be aided 16

1.4.2 Type of decision aid 17

2.0 GENERAL APPROACH TO A SOLUTION 18

2.1 General Role of Decision Analysis 18

2.2 Application of Decision Analysis
to Regulatory Decision

2.3 Scope for Partial :icision Anaiysis

2.4 Facility Evaluation 24

2.5 Technical Linkage Models 27 
3.0 DEVELOPMENT OF A SPECIAL-PURPOSE STANDARD SETTING

3.1 Specifying Target Theft Probabilities for the Regulator

3.2 A Simplified Example

3.2.1 single, certain threat with binary consequences

3.2 .2 Generalization to $\pi_{i}$ not equal to

3.3 Realistic Generalization of Example for Determination of Target $P^{*}$

4.0 CONCLUSIONS

4.1 General Modelling Recommendations

4.1.1 "Top-down" modelling philosophy

4.1.2 The "bottom-up" approach

4.2 Further Work Proposed

51

REFERENCES 
Page

FIGURE 1-1 Levels of Generality with Respect to Regulatory Options

FIGURE 1-2 Some Standard-Setting Options

FIGURE 2-1 Decision Analytic Framework

for Regulation

FIGURE 2-2 Summary Facility Evaluation

FIGURE 2-3 Some Detail of the Input-Output Relations and the Decision Analytic Model of the Decision Analysis Project

FIGURE 2-4

A Technical Linkage Model for Theft

FIGURE 3-1 A Single Certain Threat with a Binary Consequence

FICURE 3-2 A single Certain Threat with a Binary Consequence and with low Safeguard cost

FIGURE 3-3 A Single Uncertain Threat

FIGURE 3-4 Risk as a Function of 5 , safeguard Cost, for a Simple Example

FIGURE 3-5 Overview of Process-Single Threat

FIGURE 3-6 Extension to the LLL-DDI Macro-Model

FIGURE 3-7 Overview Mode'-Configurations $A$ and B, Single Threat $\mathrm{T}_{i}$

FIGURE 3-8 Overview Model-Multiple Configurations, Multiple Threats $\mathrm{T}_{1} \ldots \mathrm{T}_{\mathrm{N}}$

IIGURC 3-9 Overview Model-Multiple Configuraticns, Multiple Threats, Multiple Levels of Success 


\section{PREFACE}

This report addresses Task 3, Part B of Subcontract 7693603 from Lawrence Iivermore Laboratoxy, at the University of California, to Decisions and Designs, Incorporated. The task involves assisting the University in developing models to facilitate various applications of the MCS evaluation model being developed by the university.

The work descrited in this report was carried out under the technical monitoring of Dr. Stein Weissenberger of Lawrence Iivermore Laioratory and with continuous access to the advice of Mr. William Murphey, Director, Technical Support Branch, Division of Safeguards, Fuel Cycle and Environmental Research at the Nuclear Regulatory Iommission. 
TOWARD ANALYTIC AIDS FOR

STANDARD SETTING IN NUCLEAR REGULATION

\subsection{PROBLEM FORMULATION}

\subsection{Objective}

The objective of the present task is to develop regulation aids to help regulators and their advisors evaluate regulation options in terms of other judgments derived from formal or informal analysis. These judgments include value judgments of government officials, representatives of the public, and normative studies, bearing on the trade-offs among various possible consequences of a safeguard system. The trade-offs include technical judgments on possible threats, safeguard responses and consequences based on direct expert judgment, and techinical studies of the type performed by iawrence Livermore aná Sandia Laboratories.

To be useful, such regulation aids should efficientiy accommodate data currently and potentially available; moie important, they should be responsive to the perceived needs of factors in the regulatory decision process. However effectively conceived and implemented, a regulation aid is of no use if nobody asks for it or uses it when available.

The first objective requires a constructive, creative and well-informed modeling effort. The second requires intimate familiarity with the procedures, organizational setting, and idiosyncratic needs of pa:ticipancs in the Nuclear Regulatory Commission (NRC) regulation process.

\subsection{Problem setoing}

1.2.1 What is to be regulated - lhe facility to be regulated is currently covered by the code of Federal Regulations (CFR), Title 10 (Energy) Chapter 1 (Nuclear 
Regulatory Commission). The Nuclear Regulatory Commission has responsibility for assuring that the licensed nuclear power industry is conducted without "undue" risk arising from the malevolent use of nuclear materials. (Other risks are specified which this report does not directly address.) The primaxy instruments for safeguarding against malevolent use are material control and accounting systems which are discussed in some detail in IAEA 1976. The role of material control and material accounting in the safeguards program is described in the NRC 1978 Report of the Material Control and Material Accounting Task Force.

\section{2 .2 Current status - Present regulations, desaribed} in CFR 10, section 70, which specifies regulations dating from 1967, are currently under review, and an "upgrade rule" is due to be issued (see next section). The report for material control from the material accounting task force (NRC 1978) represents a major NRC input to the process of upgrading the rule.

\section{2 .3 Organization of NRC decision process - As} earlier indicated, any regulation aid must appropriately interface with the user of the aid, in this case, the NRC. It is, therefore, desirable to describe the organization of the NRC decision process with respect to regulation revision. The following description of that process consists of a DDI translation of a discussion between DDI analysts and a member of the NRC staff. ${ }^{1}$ Any errors or omissions should be attributed to L-:.

I. Private communication dated April 20, 1978, from Mr. Nilliam M. Murphey, Chief Technical Support Branch, Division of Safeguards, Fuel Cycle and Environmental Research. 
1. Perception of the need for revision of a regulation; done by any of:

The commission

Director, Division of safeguards (SD)

staff member

2. Task force assessment

e.g., Joint. NRC/ERDA task force on physical protection

3. Staff review of the draft task force report

4. Task force recommendation

5. Feasibility and impact review: by $R A B / S D$

(Requirements Analysis Branch/Safeguards Division)

6. Statement of conclusions by $R A B$ and ircorporation into the RAB work plan

7. Development of prototype regulation

8. SD staff review

9. SD director approval

10. NRC office review

11. Submission to the Commission

12. Incorporation of modifications

13. Issue for public comment

14. Review of comments

15. Reply to each commentor

16. Revision of rule

17. SD staff review

18. SD director approval

19. NRC review

20. Commission approval

22. Effective rule publisher

22. Licensee plans submitted

23. Plans reviewed (appropriate licensing branch) 
24. Implementation of approved plans (Iicensee)

25. Inclusion into the routine inspection cycle

In December 1977, Mr. L. Evans, of the NRC Office of Nuclear Materials Safety and Safeguards, projected the milestone for physical security upgrade (NMSS/SO): the upgrade rule would be published $b_{y}$ the fall of 1978 and implemented by early 1980. The same office envisioned publication of an MC\&A upgrade rule by the beginning of 1979 (source: unpublished charts on "Development Bases for Regulatory Dccuments").

\subsection{Regulatory Options}

1.3.1 General - Historically, the regulations for nuclear material safeguards have been written in terms of detailed technical specifications. It was rather straightforward to determine whether or not facilities satisfied those specifications. However, it was often the case that a licensee appeared to satisfy the regulations but did not completely satisfy the basic intent--for example, protection against a specific malevolent act. In addition, licensees comclained that they were being required to carry out actions which did not seem to contribute optimally to the declared objective and that if allowed freedom of protective system design, they could provirle as good or better protection for less cost.

The NRC decided to review the safeguard regulations and concluded that a regulation based more on relevant performance levels might better satisfy the needs of the public is well as the licensee, by allowing the licensee 
flexibility to design his system in any way which would provide protection acceptable to the public. Accordingly, new regulation proposals are being entertained, with particular attention to the following issues: What type of safeguard properties should be regulated? What criteria should determine their adequacy?

The properties evaluated may be unambiguously "objectively" measurable (say, based on a specific measurement or statistical procedure); or they they may be only assessable with the intervention of "subjective" human judgments (say, a probable amount of plutonium stolen, ur even the utility of the facility measured on some suitable scale). Assessable properties may be more relevant to regulation objectives, but they are controversial to evaluate and are in fact unacceptable to some NRC authorities.

\subsubsection{Level of generality - In addition to} involving either objective or subjective measurements, the properties may be at differing levels in the hierarchy of performance objectives, ranging from measurement, to control of material, to safeguard adequacy, to total facility performance. Performance objectives, in general, should be at the highest level at which compliance can be unambiguously verified. (The analysis of alternative modes of regulation may, of course, consider higher order performance measures than the regulations themselves do.)

Figure 1.1 illustrates examples of differing levels of generality with respect to regulatory options. At the most specific level, regulations involve technical specifications such as the types and locations of alarms, 


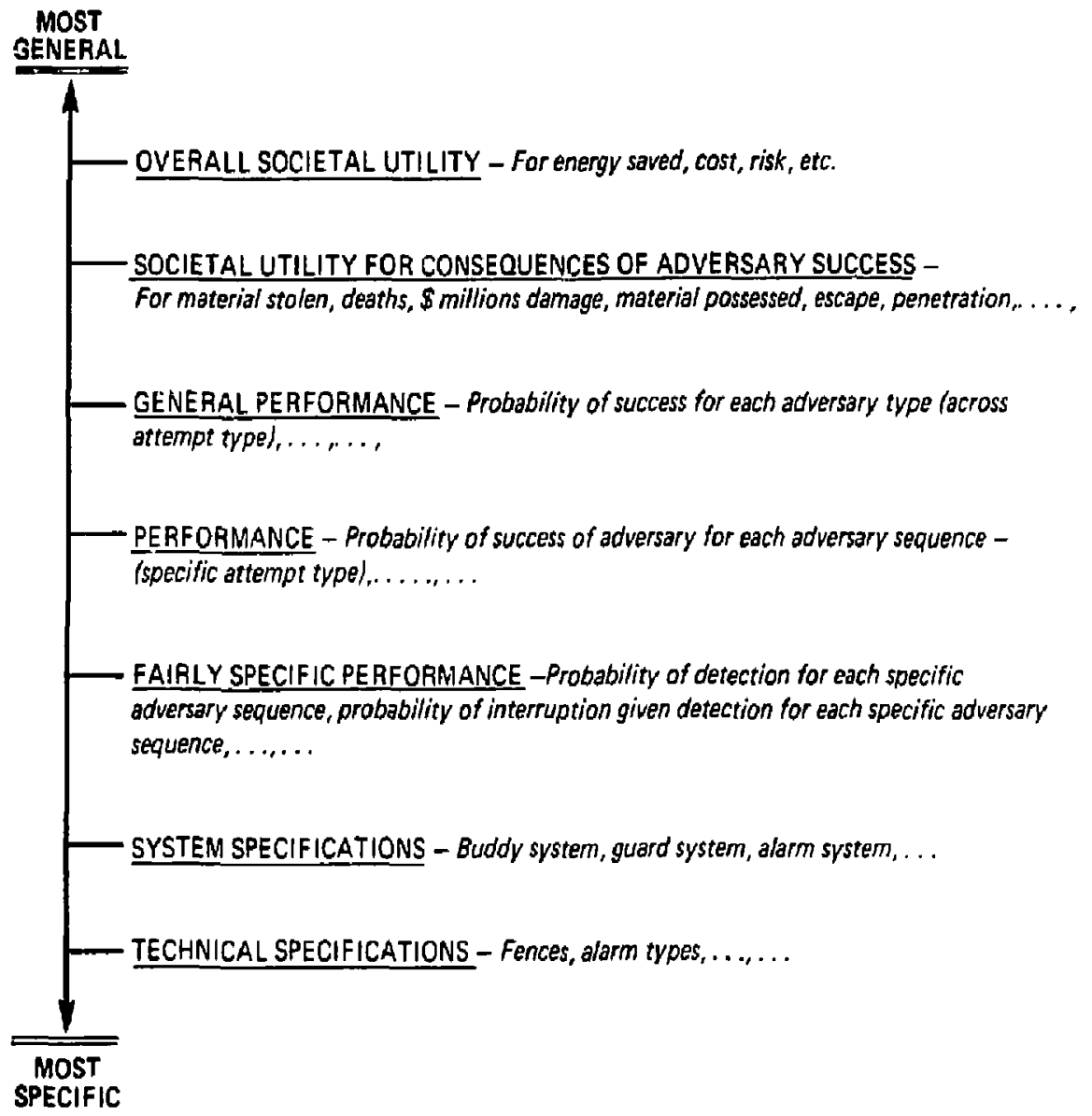

Figure 1-1

LEVELS OF GENERALITY WITH RESPECT TO REGULATORY OPTIONS 
heights of fences--and the like. Intermediate levels involve performance measures or measures of potential performance. An example is the probability of detection for each specific action sequence for each specific adversary. A more general performance measure is the overall probability of successful material removal taken across all action sequences for a particular adversary type. Even more general than the probabilities of different kinds of success are the consequences of such success. Certain consequences are far more serious than others, and the guantification of societal utility for consequences would involve assessing such trade-offs. As discussed, the more general the regulatory option, the more freedom for safegiard design, but the more difficult the implementation.

\subsubsection{2 - Multiple versus composite thresholds -} The criteria for adequacy of prorerties evaluated may be in the form of multiple thresholds applied separately to each property; or they may be in the form of a single composite threshold, to permit compensating performance. For example, current thinking is that the licensee should be required to have adequate protective capability for each possible category of adversary action sequence. But he has freedom to choose what (compensating) collection of mechanisms he employs to achieve that capability and where along the adversary action path he places the protective strength; that is, there would be multiple thresholds at an intermediate performance level.

Note that for a fixed number of properties, multi-thresholds applied to each provide a more restrictive overall requlatory process from a design point of view than Joes a composite threshold. Setting a threshold for each property is like viewing the process as a sequence of chain 
links. "The chain is only as strong as its weakest link." A composite threshold across several properties assumes that weakness with respect to one property can be compensated by strength with respect to anothts property. For example, for a given adversary sequence, it may not be necessary to design against every possible action of the adversary during the sequence if there is a point in the sequence which is unavoidable for the adversary and which can be designed against. Whether thresholds should be multiple or composite is, therefore, a function of the nature of the process, compensatory or not; and the choice of thresholds shotald involve consideration of the characteristics of the process.

\section{Existing material safeguard regulations} relating to material control involve multiple thresholds on readiy measurable variables at differing performance levels. One such performance measure is that material unaccounted for (MUF) be less than 18 of throughput at a 958 confidence level. (Note the $95^{\circ}$ confidence level can be given a precise operational determination, whereas a 958 credible interval would call for personal judgment.) It should be noted that MUF is not directly relatable to the overall objective of safeguards except in certain specific circumstances, A low MUF does not imply an absence of diversion, and a high MUF does not guarantee diversion except possibly in the simple case of no falsification of the records.

The regulation of physical protection safeguards for nuclear facilities, on the other hand, specifies in great detail exactly what protective devices are called for, even to the grade of wire to be used in fences; thus there are multiple thresholds at the lowest performance level. 
Figure 1-2 attempts to lay out the main choice dimensions for regulation in the safeguards field with illustrations for preseniing particular categories. It refers only to the setting of standards, which includes writing regulations, regulation guidelines and license conditions. Figure 1-2 does not relate to the process of actually conferring licenses or of monitoring compliance after they have been issued, though these are equally important functions for which exercise aids should be developed. The figure also limits attention to restrictive regulation options, that is, those requiring certain conditions to be met absolutely. Restrictive regulations can be contrasted with motivational regulations, which have of ten been advocated (especially by economists) and which apply rewards or penalities for divergencies from a norm.

Figure 1-2 addresses three variables with respect to standard-setting options. The first is the multiple versus composite threshold issue earlier discussed. The second variable is the subjective/objective evaluation issue: can or should objective, observable measures be established, or should subjectivity be allowed? This variable interacts with the third addressed, the level of performance evaluation. As indicated, the more general the level of performance evaluated, the more difficult are regulations to establish and enforce, and the greater is the necessity for subjectivity in the measurement process. For example, a regulation involving societal utility obviously requires the assessment of a societal utility function. $A$ regulation involving the probability of interrputing an adversary sequence involves modelling, and inherent in any modelling process are assimptions and estimates. 


\begin{tabular}{|c|c|c|c|c|}
\hline \multirow{2}{*}{$\begin{array}{l}\text { LLEVLL OF } \\
\text { PEBFORMANCE } \\
\text { EVALUATION }\end{array}$} & \multicolumn{2}{|c|}{ Mulkiple Threstrolds } & \multicolumn{2}{|c|}{ Composite Thresholds } \\
\hline & $\begin{array}{l}\text { DBDECTIVE } \\
\text { EVALUATION }\end{array}$ & $\begin{array}{l}\text { SUBJECTIVE } \\
\text { EVALUATION }\end{array}$ & $\begin{array}{c}\text { OBJECTIVE } \\
\text { EVALUATION }\end{array}$ & $\begin{array}{l}\text { SUBJECTIVE } \\
\text { EVALUATION }\end{array}$ \\
\hline $\begin{array}{l}\text { SPECIFIC } \\
\text { PROCEDUAES }\end{array}$ & {$\left[\begin{array}{l}\text {-Periodic material } \\
\text { transaction reports } \\
\text { statistical tests }\end{array}\right.$} & & & \\
\hline $\begin{array}{l}\text { MATERIAL } \\
\text { CONTROL } \\
\text { SPECIFICATIONS }\end{array}$ & $\begin{array}{l}\text { "MUF's } \leqslant 1 \% \text { at } \\
95 \% \text { "contidence } \\
\text { level" }\end{array}$ & $\begin{array}{l}\text { Detect within } \\
\text { shift/MUF's } \leq 1 \% \\
\text { with } 95 \% \\
\text { probability }\end{array}$ & & \\
\hline $\begin{array}{l}\text { MATERIAL } \\
\text { CONTROL } \\
\text { PERFDRMANCF }\end{array}$ & & $\begin{array}{l}\text { High detection } \\
\text { probability for } \\
\text { each adversary } \\
\text { sequence }\end{array}$ & & $\begin{array}{l}\text { High detection } \\
\text { probability } \\
\text { overall }\end{array}$ \\
\hline $\begin{array}{l}\text { SAFEGUARD } \\
\text { PERFORMANCE }\end{array}$ & & $\begin{array}{l}\text { Low theft } \\
\text { probability for } \\
\text { each sequence (D) }\end{array}$ & & $\begin{array}{l}\text { Low theft } \\
\text { probability } \\
\text { overall } \quad \text { (E) }\end{array}$ \\
\hline $\begin{array}{l}\text { FACILITY } \\
\text { PERFORMANCE }\end{array}$ & & $\begin{array}{l}\text { Societal risk u, } \\
\text { Energy supply u, } \\
\text { Operator } u\end{array}$ & & Total u \\
\hline
\end{tabular}

'Currently exists

Figure 1.2

SOME STANDARD.SETTIWG OPTIONS 


\subsubsection{Complexities of possible realistic options -}

Within Figure $2-2$, any particular cell can be interpreted in more than one way. A cell can refer to a regulation as written into the code of 'ederal Regulations. It can refer to the content of implementation documents such as regulation guidelines and license conditions which will typically be more specific, (for example, at a lower level of performance) but not have legal force. A cell can simply offer design aids, that is, suggestions to aid operators in designing a facility which will meet regulations. Or it can specify guidelines, addressed to the regulator, to be followed in formulating regulations and/or regulation guidelines. Such guidelines would indicate the operating properties that a regulation should have without such properties necessarily being written into the regulation. This would typically occur at a higher level of performance.

For example, the regulation as written may state, as current regulations do, that material unacr 'inted for (MUF) should not exceed 18 of throughput at a 958 confidence level (Box $A$ in Figure 1-2), or that diversion of 5 formula kilograms of plutonium should be detected within an 8-hour shift with $95 \%$ probability (Box B). Guidance to the licensee might specify a particular procedure; for example, a statistical test which if met successfully will assure, either absolutely or to a high degree, that the regulation would be met (but the licensor might satisfy the regulation some other way too) ( $\mathrm{BOX} C$ ). The regulator, in formulating both guidelines and regulations, might abide by the principle that the probability of successful diversion for a given attempt sequence should not exceed 58 (BOX D).

Furthermore, each of the three tasks, regulatior. writing, guidance to licensors, and guidance to the regulators, 
can specify more than one box entry either as an option or as a requirement. For example, a regulation might specify that a particular MIJF procedure be adopted, and also that the probabilities of theft (however established) fall below a certain level. Alternatively, the regulation might be more liberal and allow the licensor to meet either of the above conditions.

Thus, the range of possible options open to the regulator and his advisors, with all the permutations implied by the above discussion, is extremely large.

\subsubsection{Specific options to be examined - Within the} complex maze of options discussed land the many variations within them), some sharpening of focus is necessary for practical manageability. In addition, some limitation is imposed by options viewed as realistic by NRC at the present time. Attention is therefore restricted here to regulatory options under serious consideration with reasonable chance of adoption.

For this exercise, particular attention will be paid to Boxes $D$ and $E$ to identify regulation principles (rather than the regulations themselves). Thus, it is assumed that principles will be sought in the form of either composite or multi-thresholds involving subjective judgment at an intermediate performance level relating to the performance of the safeguard system. It seems likely that regulations themselves will be set at the levels of Boxes $A$ or $B$ in Figure $2-1$, though it is probably not necessary to make fir:- assumptions about this to select a regulation principle. 


\subsection{Specification of Aids to be Developed}

A regulation aid may be designed to perform a number of different roles. The regulation aid used will depend on which characteristics are most desired by the intended user and which can be most cost-effectively achieved. As earlier discussed, the hierarchy of standard-setting options ranges from specifying particular features of an MC\&A system, like the number of valves and their positions, to specifying dimensions of performance, like probability of theft. A regulation aid can be used to help decide the form of regulation--performance-based versus other--rather than any particular parameters.

In considering the nature of the regulation aid, it is important to predict realistically what might actually be implemented as opposed to accepting "blue-sky" ideas (though the latter can be at least as valuable in the long run). It. is also important to get informed response to a trial output display as soon as possible. Ideally, aid developers should be present when any feedback is displayed, partly to learn and partly to forestall possible premature rejection of the ideas.

What kind of conclusions would a regulator want to draw about a proposed standard, such that a regulation aid might help him draw them? Political and organizational implications are important to him; but he might not want to handle these explicitly, provided that the bottom line of net advantage on other dimensions is very clearly communicated. Moreover, the display need not refer to the regulator's options exactly. It can refer to possible situations which might result without modelling the linkage between the two. 
Modelling of the linkage between iegulations and facilities can be handled in a number of ways. One is to say: suppose that faciitities are exactly equated to a resultant standard (that is, disregard the possibility that the stindards will be either over-or under-met in practice). This method is easier but less realistic than actually predicting compliance.

Bearing in mind DDI's comparative experience in the application of decision analysis (relative to skills and experience available on the staffs of Lawrence Livermore Laboratory and NRC), the most natural procedure might be to use classicial decision analysis to scan the set of options under consideration and identify the one with the highest utility. The total utility would include the societal risk and energy supply implications of regulated facilities; the impact of the reg!lation process for facility operators; and, not least, the impact of the reguladion process on the interests of the regulatory agency itself. The options scanned can be at two levels: the form the standaras should take (for example, one or more probability thresholds for diversion success with different attempt scerarios); and the numerical values to put into those forms lexactly what those probability thresholda should be).

However, it is not clear that this comprehensive role is the only o.e that decision analysis should play or that it would even be necessarily its most useful role. The user may wish to make explicit only some of the considerations he will take into account and hardle others informally and implicitly, for example, the relative administrative costs of different kinds of regulatory forms. In other words, the user may need only a partial analysis of his problem. 
Noreover, he may want to use the analysis to disp.ay-possibly in many forms--rich, illuminating insights into various facets of the problem not restricted to the terse slumary.

For example, the entity evaluated by the analysis may be any of the following: the principle underlying the regulatory option, the regulatory chtion itself, a parametric characterization of facilities that regulations might lead to, or a given facility. (The last was the entity evaluated in the safeguard effectiveness model described in Brown and Feuerwerger, 1978.) The narrower the scope of the entity avaluated, the more thoroughly and perhaps more realistically it can be done, but the more, of course, that must be handied informally or with subsequent extensions of the analysis.

Again, the entities evaluated may be only partially evaluated. Only some of the dimensions of value may be considered, for example, societal risk due to an attempted diversion (as in the macro-model case), excluding other social dimensions of utility and utility of either operator or regulator.

Only part of what links the entity with its utility may be analyzed. For example, if the object of evaluation is a nuclear facility with its safeguard system, potential aspects for modelling include its technical linkage with intermediate performance measures such as the probability of detection; the inkage of these performance measures with consequences such as the amount of plutonium diverted; or the utility of these consequences. 


\subsubsection{NRC tasks to be aided - In considering the}

nature of an aid, it is useful to consider NRC tasks to which an aid could potentially make a contribution. Three aire the following:

1. Task 1: Deciding on the nature of the regulations with respect to the variables on Figure 1-2 - Should the regulations be performance based or should they be detailed specifications? Should they be different from their current form? should they be general or highly specific? Should they involve subjectivity? Should they be quantitatively expressed? Should they involve muitiple or composite thresholds?

2. Task 2: Setting parameters - Given that Task 1 is accomplished, a second task is to specify parameters for a regulation if the form is guantitative. Alternatively, parameters might be set for operational properties of a regulation in the form of threshold values. Note that these are the actual parameters in the regulations and not the desired outcomes.

3. Task 3: Determining operational properties This task involves determining the target qualities of regulations, the goals that the regulations are designed to achieve. This task involves a framework for the evaluation of regulations, regardless of how specifically the regulations and supporting guidelines are written. 
The third task is the one pursued. The evaluation framework developed should serve as a backcloth of actual regulations--as criteria against which regulations can be evaluated at a level accessible to non-technical regulators, and ultimately as $_{3}$ way of monitoring how the regulations work in practice. These operational properties could include thresholds for different measures of performance, from total utility of a regulation (including political flack), to utility of a facility, theft utility, probability of theft given attempt, and even detailed specifications.

Our assumption is that any regulation aids would not have a material impact on choosing the form of regulation rriting (Task 1). Rather, the aids would be effective in establishing principles (Task 3) for the regulation writers within the bounds of current practice and in the light of which they could perform Task 2.

\subsubsection{Type of decision aid - Is the decision aid} simply to identify the preferred option, i.e., the optimizing mode? or is it to display observations of interest that the decision maker can incorporate into his informal decision processes? If the latter, what should be displayed? Is it a complete sumary decision analysis analogous to the current macro-model? or is it one or more elements of a decision analysis?

Another somewhat separable area of inquiry is the feasible set of facility options. How high can thresholds be set in terms of what is technically possible and/or constrained by acceptable cost for all safeguards? The probability that the facility would be built at all in the face of certain regulations would be considered here. 


\subsection{GENERAL APPROACH TO A SOLUTION}

\subsection{General Role of Decision Analysis}

The recently developed methodology of decision analysis is, in principle, capable of systematically analyzing the considerations of uncertainty and value that enter into any decision. As described by Barclay et al. (1977), decision analysis is a methodology based on the axioms of expected utility theory. This methodology provides for the choice among the options available to a decision maker through the forma.: representation of the options, acts, events, outcomes, and consequences involved in potential decisions. Each option or act under evaluation is correctly related to events relevant to the outcomes of the act in a structure called a decision treo. Because there are often numerous evants and acts contingent on events that may ensue after ar option is implemented, the formal decision tree that represents these acts and events in appropriate sequential fashion often proves to be a fairly large structure consisting of many branches. Each branch represents one of the possible scenarios that may result from option implementation.

For each of these branches, the probabilities of the uncertain events that determine the outcomes of the decision are assessed, as are the utilities of the consequences associated with the outcomes of the decision/event combinations. These utilities, represented by a decision tree branch, are weighted by the appropriate probabilities with which they are associated to yield an expected utility. "Folding back" the decision tree to a particular node of the tree yields an expected utility of being at that node in the 
tree. Similarly, folding back the entire tree yields the overall expected value of the decision options.

The decision-analytic process thus formally and appropriately represents the acts and events associated with each decision option in a manner that allows the assessment of the expected utility of each option. The formal prescription of the "Optimal" decision is but one advantage of this process. Of major value is the structuring of the decision process which forces logical consideration of all relevant acts and events. The thought process that goes into this analysis forces an organized look at the entire problem that often has value in itself. Likewise, this structured look can be a partial, as opposed to a full, analysis of the problem. Whatever the degree of analysis, those variables to which the decision is most sensitive are identified and are available for further analysis. Similarly, if a complete analysis is conducted, all variables affecting the value of an option and associated uncertainties are organized into a meaningful framework.

A particular area or sub-topic of decision analysis is multi-attribute decision analysis. Put simply, this is a methodology based on the principles of decision analysis that provides for the quantification of the value of a complex, multi-attributed alternative. Thus, the decision to implement a specified set of MC\&A procedures would eventually leaó to a set of outcomes, such as material stolen, deaths, millions of dollars of damage, material possessed, adversary penetration, and adversary escape. Multi-attribute utility assessment procedures are utilized to assign a value to the multi-attributed alternative represented by a particular combination of these outcomes. 


\subsection{Applicaticn of Decision Analysis to Regulatory Decision}

As a part of a risk assessment study of material control systems being carried out by Lawrence Livermore Laboratory, multi-attribute decision analysis is being used by DDI and others to contribute to the evaluation of alternative regulatory forms. More particularly, it is intended to provide information which will lead to an informed choice of adequacy criteria, that is, the determination of performance thresholds which licensed facilities should meet.

For example, the impact of material safeguard regulaion on total societal utility attributable to nuclear Leprocessing plants can be analyzed by decomposing the utility into the following components: societal risk from diversion of detonatable material resulting from theft; cost and other facility-specific criteria inpacting licensees' interests; energy supply and other societal values related to diversion; and utility to the regulator (NRC) including political and administrative implications. Decision-theoretic models that can be developed essentially link regulatory options to such utility components through probabilistic consequences such as: the properties of nuclear facilities meeting regulations; different types of adversary attempts; and the outcomes of those attempts.

current decision-analytic efforts address only a restricted segment of the total problem (see Brown and Feuerwerger, 1978) and are mainly concerned with direct risk from a theft attempt. Figure 2-1 gives a schematic representation of how the classicial decision analysis paradigm might be used to compare any specified regulatory options in a way which encompasses the probable impact of alternatives 


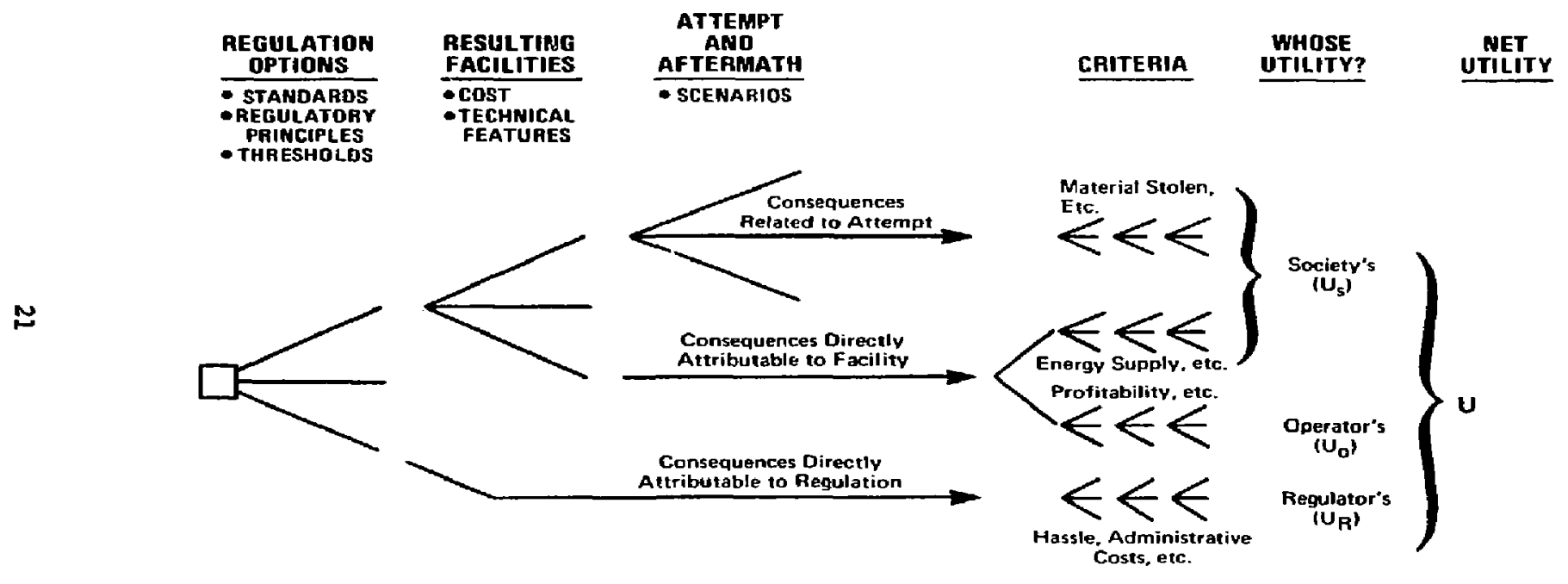

Figure 2-1

DECISION ANALYTIC FAAMEWORK FOR REGULATION 
on the key interests involved--those of the public (Society's), the nuclear industry (Operator's) and the regulating agency (Regulator's). In principle, all relevant considerations of uncertainty and value trade-offs can be explicitly handled in a decision tree (or equivalent formulation) within this general framework.

The decision to be faced involves the regulation options discussed in parts of section 1.0. As indicated, the options chosen will lead, with varying probabilities, to resulting facilities; the acts and events by which that occurs can be modelled. Similarly, the resulting facilities will lead, with varying probabilities, to different kinds of attempts by different adversaries. A model can be created for probability of adversary attempt which links facility characteristics and adversary characteristics to yield a probability distribution over different kinds of attempts. Given a particular attempt by a particular adversary, any of several scenarios can develop. Again, given a particular system for material control and accounting as well as a physical security system, a model can be developed for addressing the uncertainities associated with probabilities of detection, interruption, material lost, and the like. This model would relate to the attempt and aftermath (see Figure 2-1).

Given the results of the attempt and aftermath, there are numerous outcomes such as those listed earlier, which include material stolen, deaths, dollars of damage, viaterial possessed, and the like. These outcomes, shown under the "Criteria" section of Figure 2-1, are related to the "Whose Utility" question next illustrated. The regulator's problems, administrative costs, and the like determine UR, the regulator's utility. These criteria are consequences directly 
attributable to regulation. Similarly, there are consequences attributable to a facility, such as energy supply, profitability, and the like, which affect both operator utility, $U_{0^{\prime}}$ and also societal utility, $U_{s}$. Also, consequences related to any attempt such as material stolen or possessed, to deaths, and the like enter into the assessment of societal utility.

The macro-model described in Brown and Feuerwerger (1978) illustrates how these issues are addressed in assessing the effectiveness of safeguard for nuclear processing plants, with emphasis on material control and accounting systems. In that work, a multi-attribute utility function is developed for a circumstance characterized by six outcome dimensions for a theft attempt. This macro-model, although utilizing a few highly aggregated variables, is a good example of a linkage model that can be of great benefit in examining variables of interest to the regulator. As discussed, each of the sections indicated in Figure 2-1 can be modelled in much greater detail if necessary.

\subsection{Scope for Partial Decision Analysis of Regulation Options}

As noted earlier, the role of decision analysis need not be limited to a complete pass at the total decision problem; it can analyze and illuminate particular considerations or classes of consideration within the total problem (see Section 1.4.2 above).

The main special-purpose analyses embarked upon or considered for this effort include: 
- modelling safeguard effectiveness for a given facility (see Brown and Feuerwerger, 1978);

- assessing components of the above macro-model, e.g., attempt probabilities, safeguard response, or the attribute utility functions for societal risk (covered by special studies by prime contractor, Lawrence Livermore Laboratory, and other sub-contractors);

- determining optimal performance characteristics of a regulated fasility, e.g., conditional probability of adversary success (addressed in Section 3.0).

- modelling technical linkage between facilities/safeguard parameters and facility performance measures.

The separable modeliing activities discussed--some completed, some underway, and some open for further consideration--may be either used as stand-alone exercises or integrated into one modelling package for evaluating a facility. These modelling activities may also be used as sources of input to an overview model which would essentially be a higher order macro-model. Based on the same philosophy dascribed in Brown and Feuerwerger (1978) for macro-models, such a model could be quantified in any of several ways: by direct assessment, by accepting as its input the output of modular models, or as the result of subjective evaluation of several alternative sources of input.

\subsection{Facility Evaluation}

Figure 2-2 develops the top two-thirds of Figure 2-1, that is, the modelling of that part of total utility attributable to a facility (rather than attributable to the regula- 


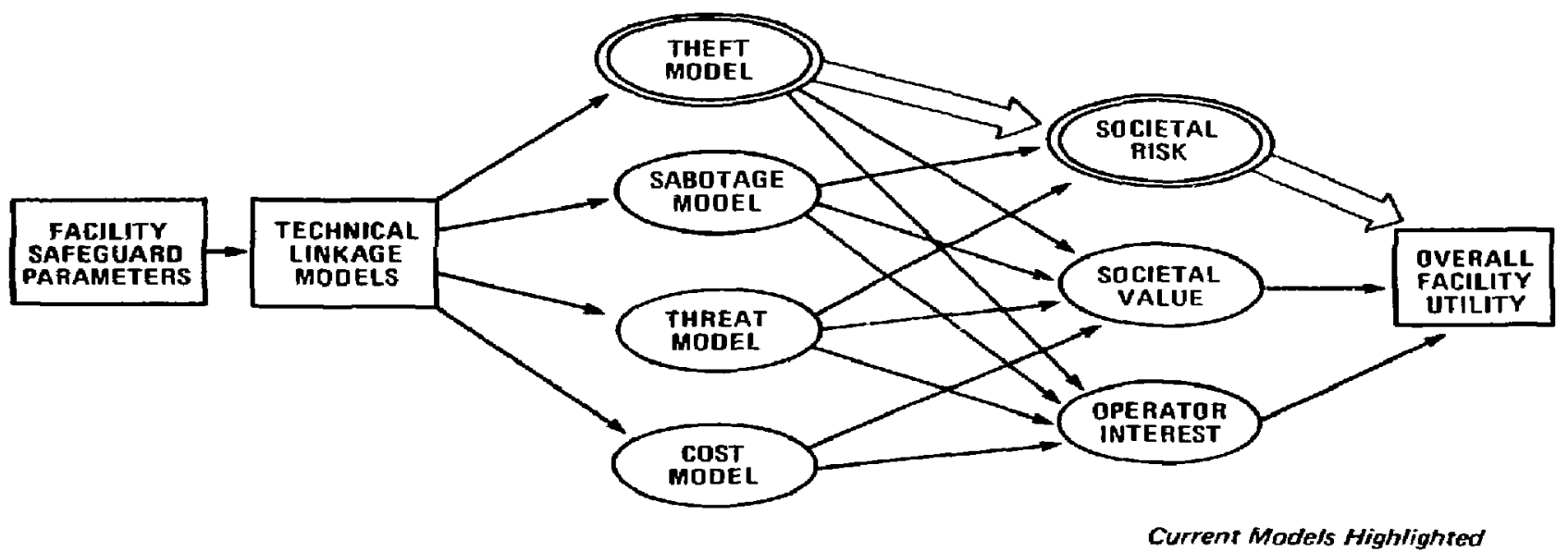

Figure 2-2

SUMMARY FACILITY EVALUATION 

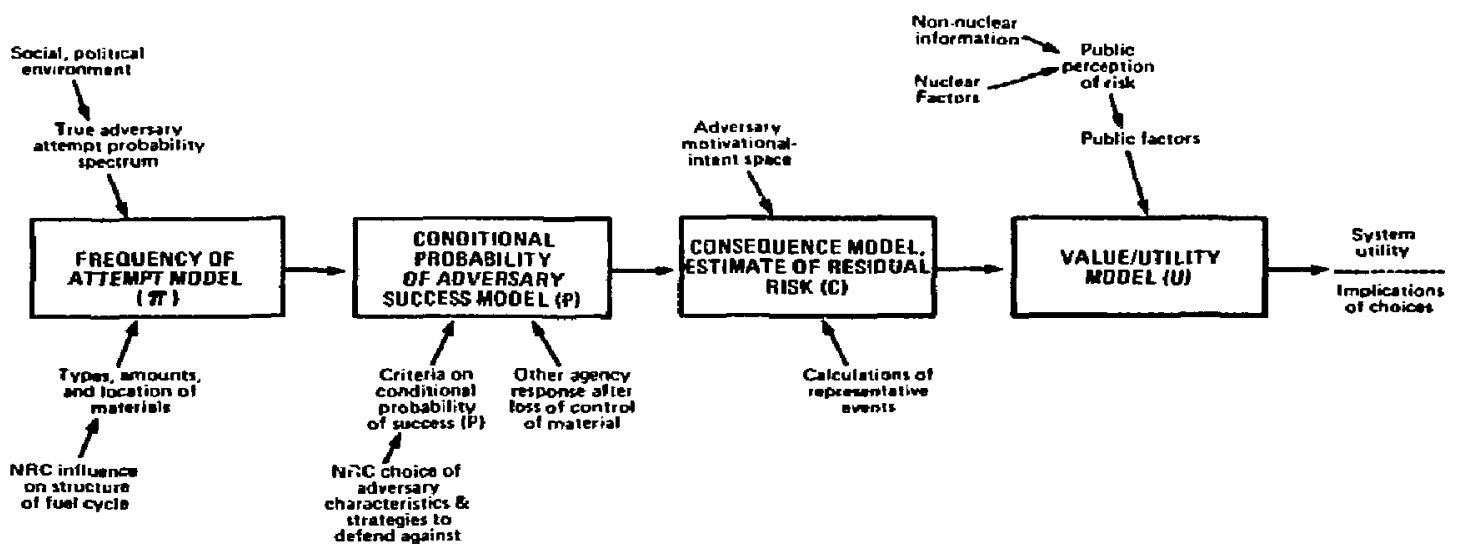

Figure 2-3

SOME DETAIL OF THE INPUT-OUTPUT

RELATIONS AND THE DECISION ANALYTIC MODEL OF THE DECISION ANALYSIS PROJECT* 
tion per se). The ringed items are modelling activities that mediate between a facility (with its safeguard systen described in terms of general parameters) and the expected utility. Successfully implemented, a total modelling activity of this form would enable the calculation of the utility of any facility in terms of its safeguard and basic parameters. An alternative representation of general issues involved is given in Figure 2-3, which is reprocuced from an unpublished working paper of Mr. William Murphey of NRC relating to facility evaluation.

The emphasized double rings in Figure 2-2 represent. modelling activity covered by the macro-model described in Brown and Feuerwerger (1978). They express the societal risk component of utility of a facility in terms of key performance characteristics such as probabilities of detection and interruption of a theft attempt. Remaining to be modelled are the other major determinants of a facility's utility: malevolent action risks other than theft (sabotage and threat) on the one hand and facility cost on the other.

\subsection{Technical Linkage Models}

Technical linkage models would predict such safeguara and cost performance measures in terms of more directly measurable technical featurt 3 of a facility, such as might appear in a regulation--for example, the periodicity and scale of material accounting procedures, rules covering material unaccounted for, the maximum period within which a significant theft is detected, and so forth. Much modelling activity of this kind has been undertaken or sponsored by Lawrence Livermore Laboratory but not exactly in the form 
indicated here. Therefore substantial scope exists for summary modelling activity at this level.

An overview of the modelling process in the development of a technical linkage model for theft is illustrated in Figure 2-4. on the far left are dial settings representing technical features of a facility involving material control and iccounting (MC\&A) as well as physical safeguards (P.S.). The technical linkage models relate such parameters to performance assessments such as attempt probabilities, detection probabilities, interruption probabilities, and outcome predictions. These performance assessments serve as inputs to the theft model which, in turn, iinks them to societal risk and utility. This is accomplished by relating outcomes and consequences to performance measures and to utilities assessed for these outcomes and consequences. 


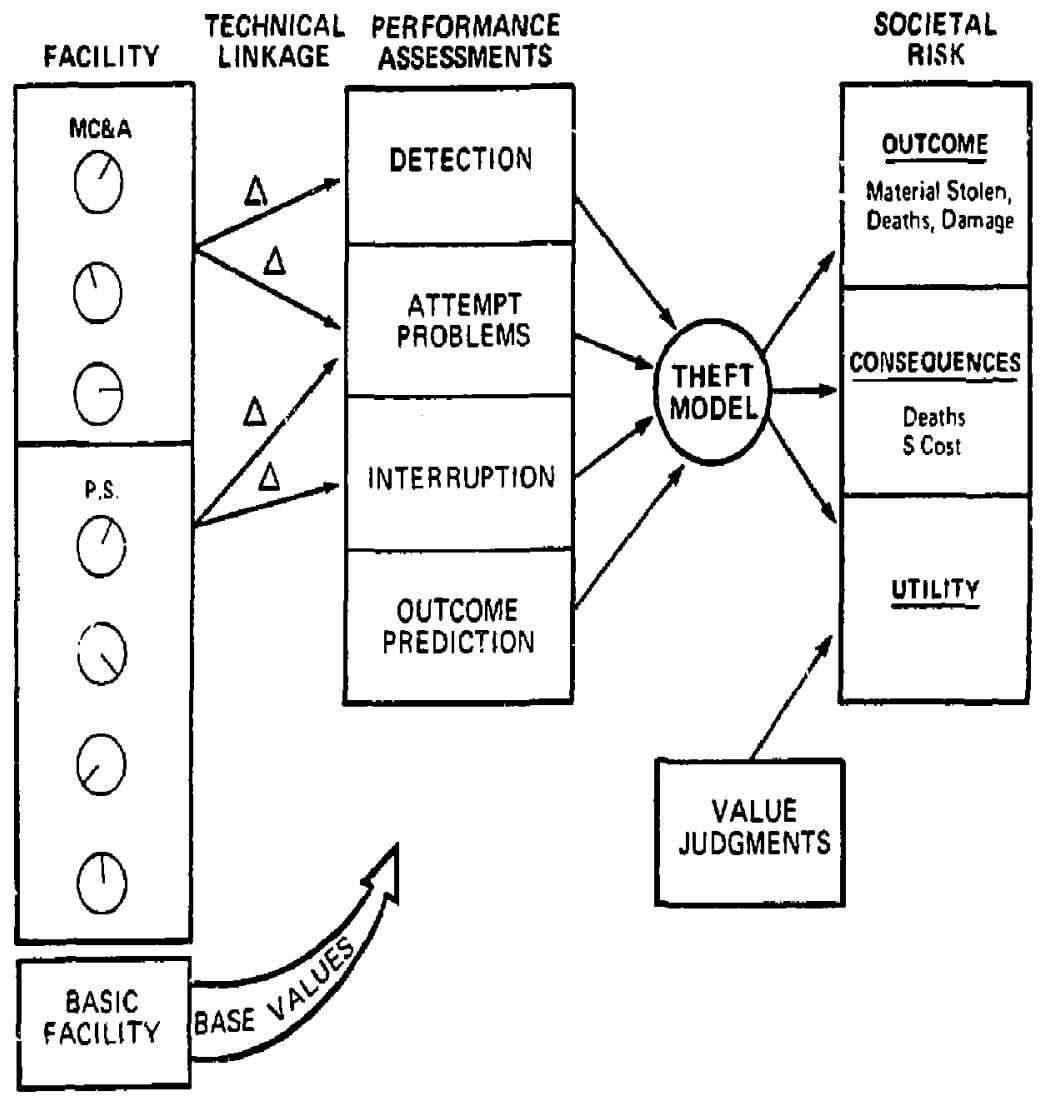

Figure 2.4

A TECHNICAL LINKAGE MODEL FOR THEFT 


\subsection{DEVELOPMENT OF A SPECIAL-PURPOSE}

STANDARD SETTING

In this section a plan is outlined for developing a special-purpose regulation aid along one of the many fossible lines outlined in Section 2.0.

\subsection{Specifying Target Theft Probabilities for the Regulator}

A key feature of any nuclear safeguard regulation and of any facility regulated is the probabiliti of successful theft, say given a specified attempt, during one year. Other things being equal, one could wish this probability to be as low as possible. However, since the lower such probabilities are in general, the higher the cost to the operator; the lower the supply of nuclear energy to the nation, the greater the loss of civil liberties for plant personnel, and

so on. Accordingly, the benefits of lowered threat probability should be traded off against the costs of safeguards to yield theft probabilities that are neither too high nor too 10w as a criterion for regulation. Determining the values at which those probabilities should be set is the task now addressed.

When the requlations are actually written, of course, they may not make explicit reference to theft probability at all, but Iather to lower order, more verifiable pexformance measures, cile setting of which would be juaged by the desired probabilities. If the probabilities were specified in the actual regulation, they would no doubt appear as minima, since the operator's motivations would likewise push them to be minima. These minima might also be set above or below the targets to take into account the regulator's judgment of how liberally or conservatively the regulations would be interpreted. 
The regulation target can be expressed in a number of different forms. The target can be a single conditional threshold applied to all types of threat scenarios, or different thresholds could be specified for different scenario types. Before discussing that issue, discussion of some general background and terminology is necessary.

Suppose that different threat scenarios, defined by type of adversary, type of target, means used, and so forth, are indexed by $i_{i}$ that $\pi_{i}$ is the Erobability that the $i^{\text {th }}$ threat will occur; that $P_{i}$ is the conditional probability that the $i^{\text {th }}$ attempt will be successful; and that $c_{i}$ is the consequence of a successful threat $i$ and $U\left(c_{i}\right)$ is interpreted as the utility of $c_{i}$ to the regulator.

The target threshold could be the product of $P_{i}$ and $\pi_{i}$ which gives the unconditional probability of success for a given scenario, again, either individually or as a single threshold for all scenarios. Or the threshold could be expressed as the sum of such products over all scenarios, giving an unconditional probability of theft success for the regulated facility. Yet again, control coula be exercised over the risk associated with the $i^{\text {th }}$ threat, defined as $r_{i}$, the product of $\pi_{i}, P_{i}$ and $U\left(C_{i}\right)$ with threat-specific targets $r_{i}$ or a common target $I^{*}$ for all threats. The variable $r_{i}$ is the expected utility of the $i^{\text {th }}$ threat. Alternatively, the target could be $R$, the sum of the $r_{i}$ 's interpreted as the expected threat consequence for the facility. Of course, any or all of these targets can be tested against any particular regulation.

$R$ is most comprehensive target thus far discussed and comes closest to measuring the utility of the regulated 
facility. However, $R$ is not quite comprehersive because it excludes two considerations: First, it treats the outcome of a threat as a binary event, i.e., success or fallure, whereas in fact there exists a rich variety of possible outcomes related to degree of penetration, capture, amount of plutonium ever possessed ard the amount actually diverted (as discussed and modelled in the macro-model described in Brown and Feuerwerger, 1978). In addition, $R$ takes no account of the relative cost of affecting any given reduction and risk for different threats. Thus $R$, as defined, would fail to distinguish between two facilities of equal expected risk, one of which was achieved at greater expense, because the one facility addressed threats more expensive to control than did the other. This may not be a serious problem since it can be assumed that the operator will attempt to achieve any given total risk, $R$, at minimum expense.

Any of the other lower order target formulations can effectively be reduced to $R$. Any set of $P_{i}$ 's and expected values for $\pi_{i}$ 's implies a value for the unconditional probability of success; and this in conjunction with expected $U\left(C_{i}\right)$ gives expected $R_{i}$, conditional risk, and so forth. However, the higher the order of measure, the more flexibility in how it is met at lower levels, and it is not clear that there is anything to be gained by giving up that flexibility by specifying lower order targets. This is an issue open to close examination. There are, however, serious objections to specifying a single target for all threat scenarios whether a conditional probability, $\mathrm{P}^{*}$, uncondicional probability, $\pi P$, or expected risk, $I^{*}$, since such a target is a direct function of how the threats are defined, and this definition can be quite arbitrary. 


\subsection{A Simplified Example}

This section develops an example of how a target can be set; it proceeds from a simple representation of the problem to one that is more complex.

\subsubsection{Single, certal' threat with binary consequences -} Figure 3-1 illustrates the case in which a single threat occurs with probability 1.0 , that is $\pi_{i}=1.0$. Then $P_{i}=P$ (success) can vary from 0.0 to 1.0 . As $P$ increases, two costs vary. One is labelled $E$ (cost of attempt), tue expected cost of the attempt which is, in fact, the expected utility of the attempt $P_{i} v\left(C_{i}\right)$ where $U\left(C_{i}\right)$ is appropriately defined. This cost is illustrated as a inear function of $P_{i}$, an unnecessary restriction although it is no doubt the case that $U\left(C_{i}\right)$ is a monotonic, non-decreasing function of I'

A second cost is illustrated as a function $P_{i}$ : the safeguard cost which is assumed to be a decreasing function of $P_{i}$. As $P_{i}$ approaches 1.0 , the cost approaches: zero. Similarly, for $P_{i}$ near 0.0 , the cost may be very high. It is assumed that for any setting of $P_{i}=P$, there is a known safeguard cost $s_{p}$, the minimum cost among safeguard systems that achieve such a $P$. The total cost of the attempt is then the sum of the two costs, which is shown as the cotted line for total cost. Given the criterion of minimizing total cost, there is an optimal, non-zero value of $P$ that achieves minimal total cost. In Figure $3-1$, this value is about .25. Figure 3-2 illustrates the same example as that in Eigure 3-1 with a lower safeguard cost function. As illustrated, in this case the optimal $P$ is closer to 0.0 . 


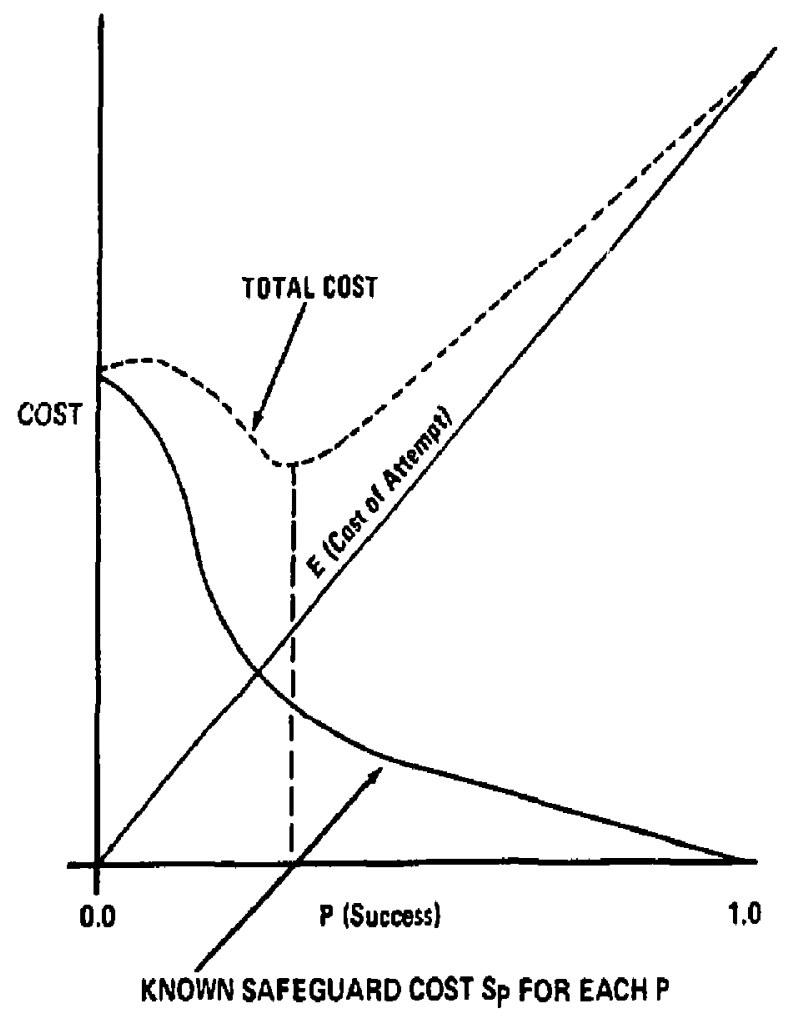

Figure 3.1

A SINGLE CERTAIN THREAT WITH A BINARY CONSEQUENCE 


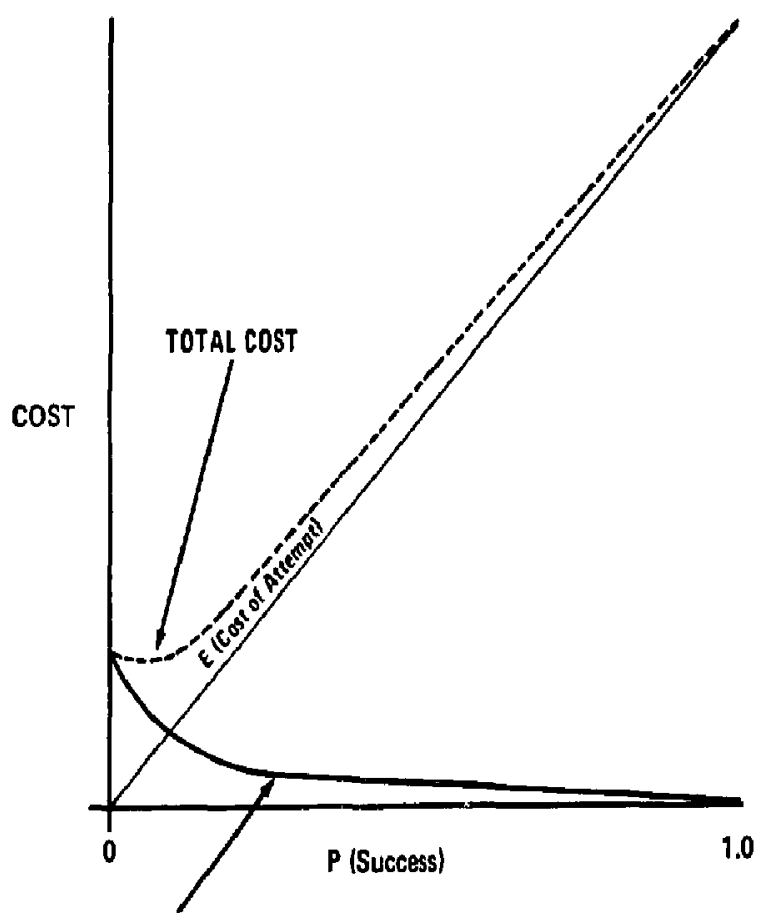

KNONIN SAFEGUARD COST SP FOR EACH P.

Figure 3-2

A SINGLE CERTAIN THREAT

WITH A BINARY CONSEOUENCE WITH LOW SAFEGUARD COST 


\subsubsection{Generalization to $\pi_{i}$ not equal to 1.0 - in}

Figure 3-3, the example is generalized. It is assumed that for an uncertain threat where $\pi_{i} \neq 1,0, \pi_{i}$ is a function of safeguard cost $s$ as illustrated. That is, as $s$ increases, there is a deterrent effect which reduces the probability of the attempt. since $\pi_{i}$ and $p_{i}$ are both decreasing functions of $S$, the product $\pi_{i} P_{i}$, or simply denoted as $\pi P$, is a decreasing function of $s$; or alternatively, there is a known cost function $S$ which is a decreasing function of $\pi \mathrm{P}$. Such a function is illustrated in Figure 3-3. Again, there is an optimal non-zero value of $\pi P$ for which the total safeguard cost is minimized.

The relation between $S$ and $\pi P$ is not a simple one because for a given specified value of the product, there are numierous combinations of $\pi$ and $F$ that yield a specific $\pi P$ product. That is, the same overall probability of adversary success can ba achieved through heavy emphasis on either deterrence or detection and interruption given an attempt, or through some intermediate level of emphasis on each. However, for a given $\pi P$ (and thus associated utility holding all other things fixed), a regulator will theoretically minimize cost, thus relating a single facility and safeguard cost to each $\pi P$ value. There exists, then, a function relating $P$ to $S$ and a function relating $S$ to $\pi P$.

In Figure 3-4, the example is extended to include $r_{i}=U\left(C_{i}\right)$, where $C_{i}$ is the single conseguence of the success of the attempt, and $U\left(C_{1}\right)$ is the utility of that consequence. Dropping the subscript $i$, as earlier discussed, $r=\pi P U(C)$. Alternatively, since there is a function relating $S$ to $\pi P$, there is likewise a function relating $S$ to $\pi \mathrm{PU}(C)$, and hence there is a function $g$ such that $r=g(S)$, some decreasing 
WITH $\pi \neq 1.0, \pi \&$ P BOTH AS FUNCTIONS OF $S$
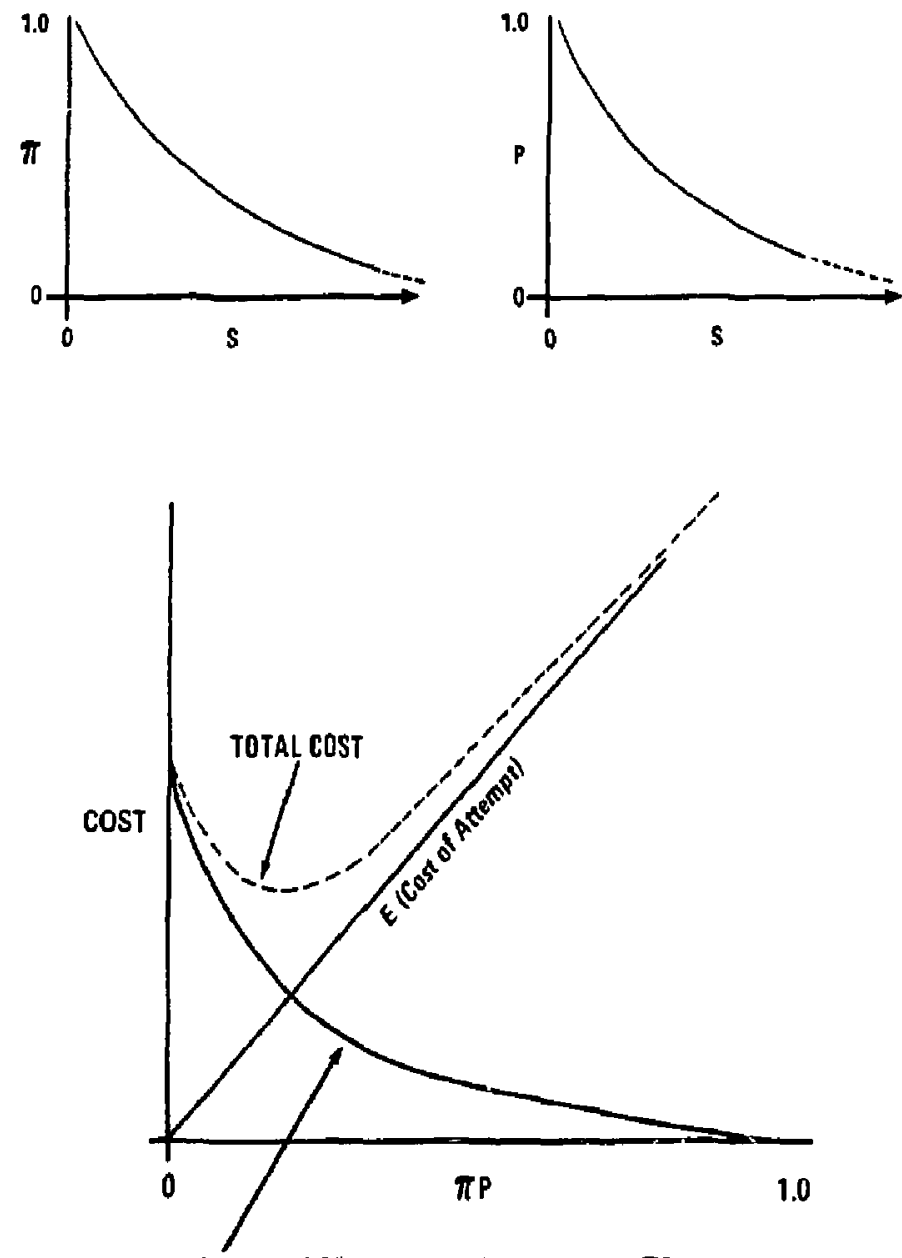

KNOWN COST OF SAFEGUARD FOR $\pi P$

Figure 3-3

A SINGLE UNCERTAIN THREAT 


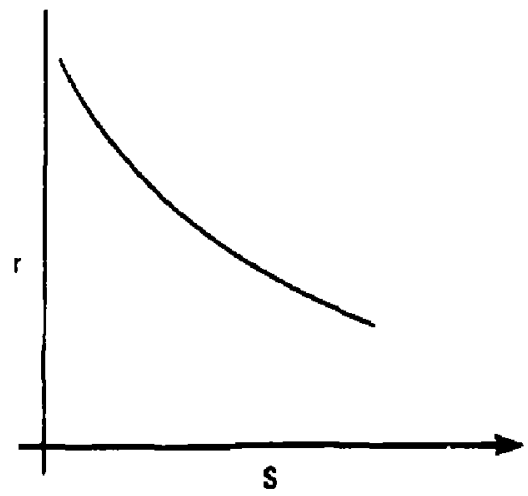

$$
\begin{gathered}
r=\pi P U(C) \\
\pi P=f(S) \\
I M P L I E S \\
r=g(S)
\end{gathered}
$$

Figure 3.4

RISK AS A FUNCTION OF S, SAFEGUARD COST, FOR A SIMPLE EXAMPLE 
function of $S$. Thus, just as there is an optimal level of $P$ or $\pi P$, there is also an optimal level of I such that tota!. overall cost is minimized, and the regulator can aim at that value of $r$. Next, it is desirable to generalize this simple example to the non-binaty outcome and multiple threats.

\subsection{Realistic Generalization of Example for Determination of Target $p^{*}$}

A general overview of the regulation process appears in Figure 3-5. On the left, regulation optlons, at whatever level, result in alternative facilities or system configurations. (Recall that the goal of this effort is not to indicate how regulations should be written to achieve specific goais. Rather, the effort is aimed at a framework for evaluating what the goals should be.) Associated with each configuration are two kinds of measures: the cost and the system parameters--as discussed in sections 3.1 and 3.2 . Such paramenters include the probability of attempt $\pi$, the probability of success $P$, the resultant consequences $c$, and the like. (Thus fax, the outcome of an attempt has been a binary event, success or fajlure. Obviously, the more realistic case is that the outcome of an attempt can involve varying degrees of success.) Then the total utility attached to a facility is a sum of the facility cost and the chosen measure of the utility of the consequences.

A decision analysis would approach the problem by considering each safeguard facility option. For each configuration, the resulting costs and system parameters can be modelled. Current or potential special studies by DDI and other contributors to the Lawrence Livermore research effort have attacked various aspects of this problem. For example, the DDI macra-model discussed earlier elicited assessments 


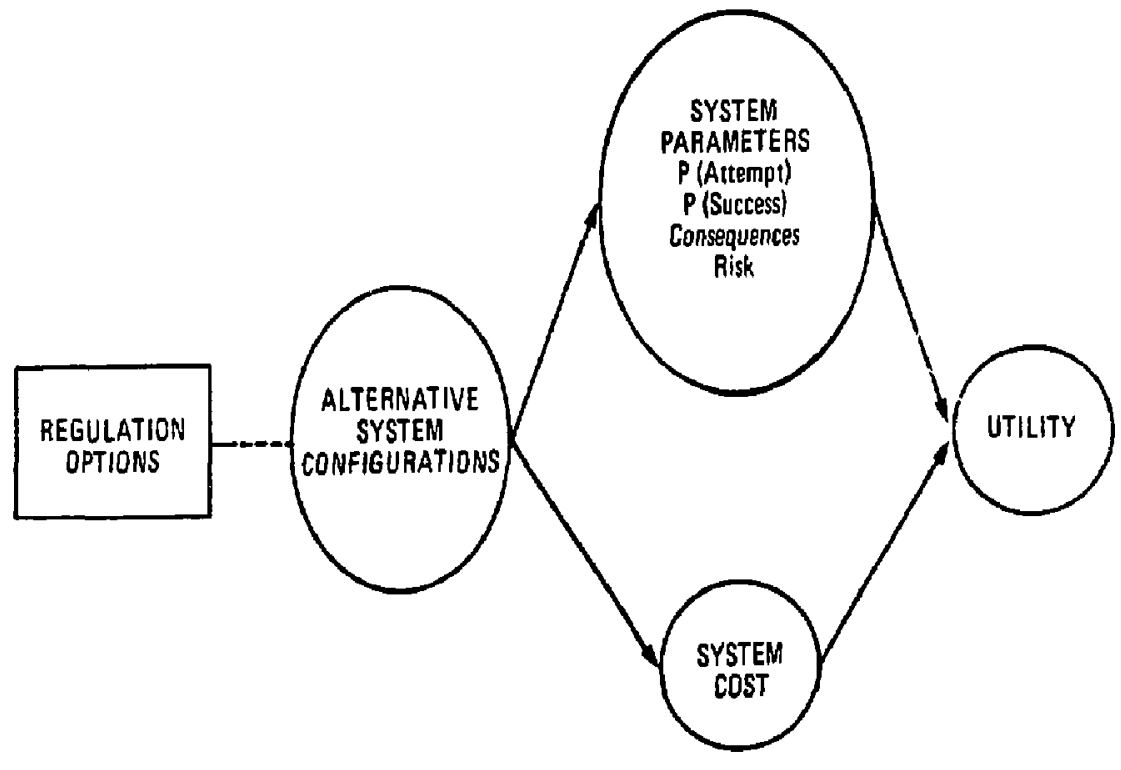

Figure 3.5

OVERVIEW OF PROCESS - SINGLE THREAT 
of the form illustrated in Figure 3-6. However, the macromodel at its current stage of development does not model either safeguard cost or parameters explicitly. It would need to be extended by a technical linkage model (see Section 2.5). Ultimately, the quality of the assessments in the macro-model could be enhanced by integrating the findings of special-purpose assessment models currently under development or planned by DDI and others. Examples are adversary models, response models, and utility models.

Given models that link regulations to configurations and configurations to cost and other parameters, decision analysis models sucin as the one used to develop the macromodel can link the outcomes and cost to overall utility. The process of determining the level at which to set a parameter selected as a target for regulation then consists of calculating the maximum expected utility and folding back the decision tree to the point at which the parameters occur. The parameter levels associated with the maximum experted utility then become the basis for regulation goals.

Figure 3-1 involves a single threat and a binary event consisting of attempt success or failure. At $P=$ approximately .25, the total cost, consisting of safeguard cost and societal cost (the inverse of the utility), is minimized. Technical models must link facility properties to safeguard costs and to the conditional probability of the success of the single adversary. The utility model (such as the macromodel) then establishes the expected cost of attempt and completes the entire modelling process. Folding back consists of collapsing the modelling structure back from the point (in this case) of minimum total cost (maximum utility) to the point at which $\mathrm{P}$ is set, The regulators can then establish that for the given threat, $P$ should be no more than the value assoclated with the minimum cotal cost. 


\section{$A D H O C$}
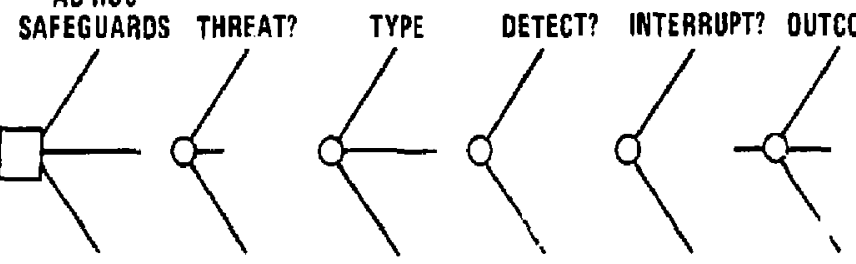

U

1

Figure $3-6$

1 EXTENSION TO THE LLL-DDI MACRO-MODEL 
It is assumed that the facility designer bears the cost of building the facility. Therefore, no specification with respect to cost need be set. If the facility designer or operator attempts to, or does in fact, pass on facility costs to the consumer in the form of increased energy costs, this must be accounted for in the calculaticn of the overall facility utility, probably as a societal cost. The general philosophy here is that the governmest may not be as ingenious as the designer and, as a result, does not optimize with respect to design. The designer should be able to achieve the desired regulation goals at or below the safeguard cost in the government model. In that sense, the cost in the government model may in fact be conservative toward the high end. The regulator, nonetheless, needs to know only that the given regulation goal can be achieved at or below the calculated cost. The rest is up to the designer.

Figure 3-7 illustrates this process for the simple case of a single threat, two potential configurations, and a hinary event--siccess or failure. Suppose $U_{A}>U_{B}$. The legulator could then choose to state that the probability of success be no more than $P_{i A}$. He knows that system configuration A can provide such a value, but he does not specify $A$, Rather, he leaves it to the facility designer/operator to achieve the results. Perhaps the designer/operator can do better--perhaps by making different trade-offs with respect to how the $P_{i A}$ is achieved. But he must do as well as the specified regulation goal. Alternatively, the regulator could choose to regulate with respect to the risk $r_{i}$. The principles are the same.

Generalizing to multiple threats, $T_{1} \ldots T_{1} \ldots T_{N}$, is rather straightforward, as illustrated in Figure 3-8. Suppose $U_{A}>U_{J}$ for every system $S_{J}(J \neq A)$. The regulator, 


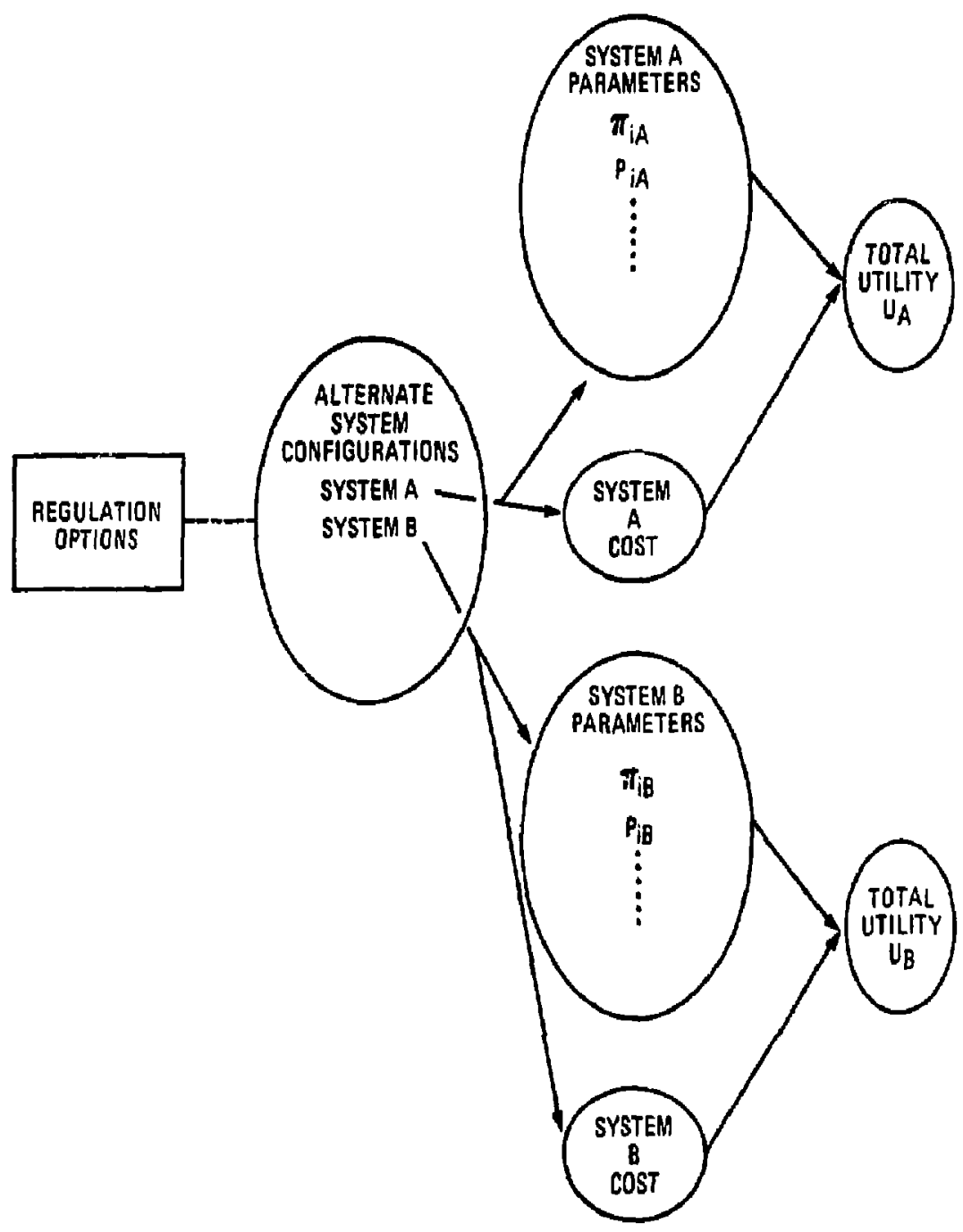

Figure 3.7

OVERVIEW MODEL -

CONFIGURATIONS A AND B, SINGLE THREAT $T_{i}$ 


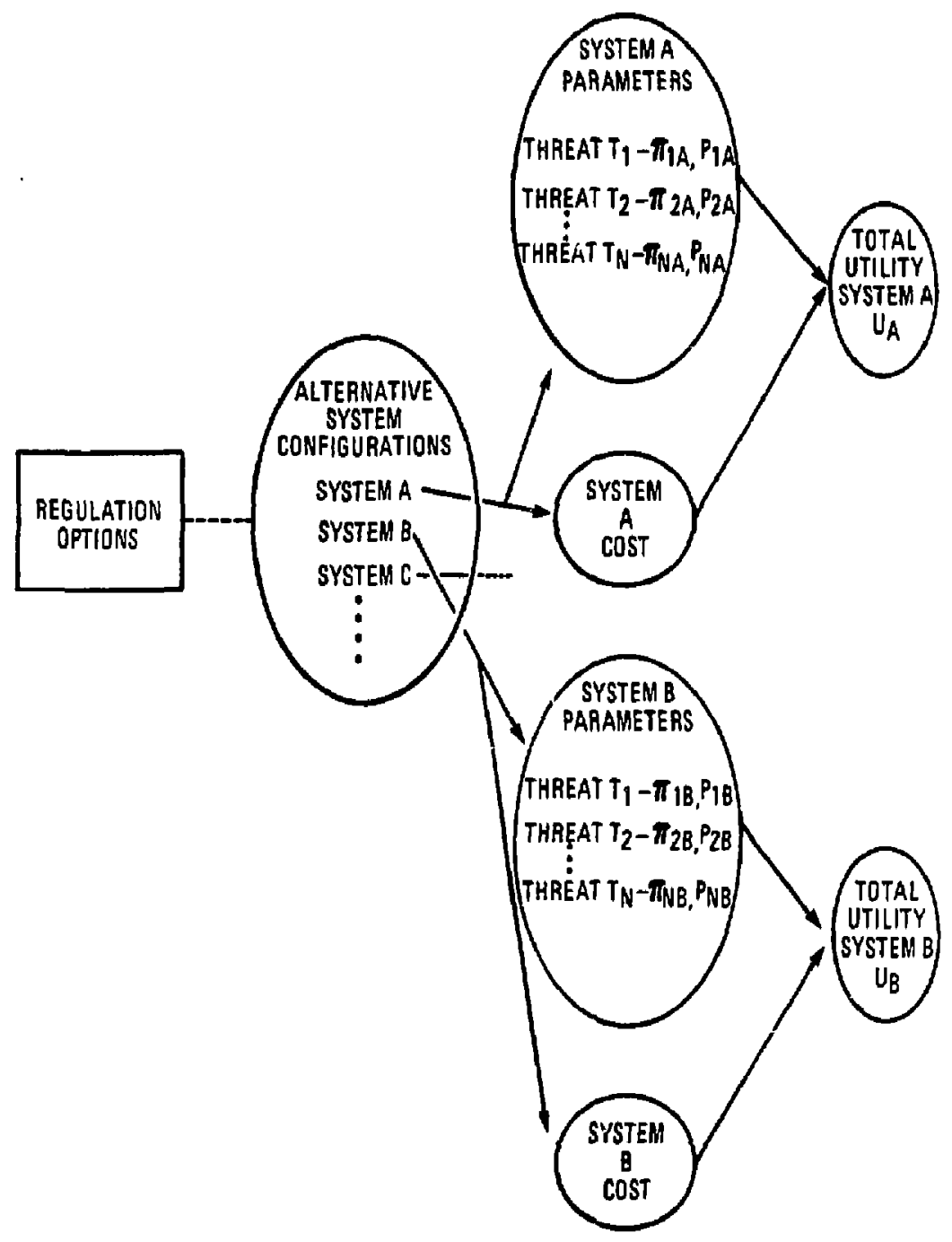

Figure 3.8

OVERVIEW MODEL -

MULTIPLE CONFIGURATIONS, MULTIPLE THREATS $T_{1} \ldots T_{N}$ 
if regulating at the level of $P$, would state that the threshold vector $P^{*}=\left(P_{1}, P_{2}, \ldots, P_{N}\right)$ would be $\left(P_{1 A}, P_{2 A}, \ldots, P_{N A}\right)$.

The next generalization can address the binary event, success or failure. Suppose there exist several (m) levels of success denoted as $o_{1}, O_{2}, \ldots, o_{m}$. suppose, for simplicity, that these levels are the same for each kind of threat $T_{i}$. Then each level of success must be mapped into a set of consequences for which a utility is assessed. The system $A$ section of the overview model is illustrated in Figure 3-9. suppose again that $U_{A}>U_{J}$ for every $J$. The regulator can state that for threat $T_{1}$ ' the threshold probability vector $\mathrm{P}_{\mathrm{T}_{1}}^{*}$ is $\mathrm{P}_{\mathrm{T}_{1}}^{*}=\left(\mathrm{P}_{1 \mathrm{Al}}, \mathrm{P}_{1 \mathrm{~A} 2}, \ldots, \mathrm{P}_{1 \mathrm{Am}}\right)$. Then the threshold vector $P^{*}$ is a vector of vectors.

$$
\mathrm{P}^{*}=\left(\mathrm{P}_{\mathrm{T}_{1}}^{*}, \mathrm{P}_{\mathrm{T}_{2}}^{*}, \cdots, \mathrm{P}_{\mathrm{T}_{\mathrm{N}}^{*}}^{*}\right)
$$

And, as discussed in Section 3.2, the regulation goal can be at the level of $r_{i}$, the risk for each threat or even $r_{j}$, the risk for facility $J$. Generalizations follow the pattern illustrated.

In the entire process thus far discussed, it must be possible to link the parameters chosen for regulation to a safeguard cost. This linkage is accomplished in this example by single-threading back through the decision-analytic model to the facility design that maximizes total utility. The costs and parameters chosen are those associated with that facility. It is then left to the facility designer/operator to achieve the regulation goal thresholds. It is assumed that the designer will not exceed the cost threshold, and that if he does, he will not pass the increased cost on to the consumer. In practice, however, such assumptions would need to be closely examined. 


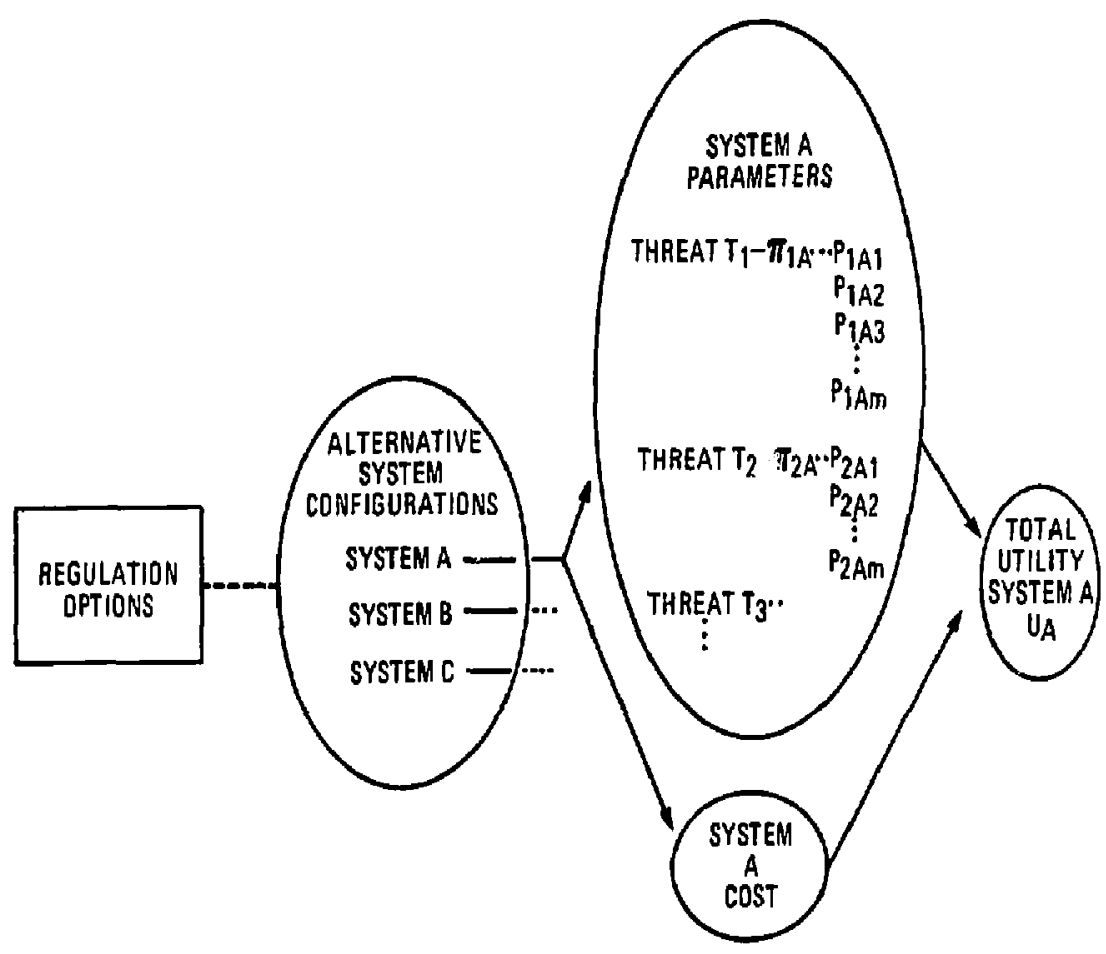

Figure 3.9

OVERVIEW MODEL -

MULTIPLE CONFIGURATIONS, MULTIPLE THREATS, MULTIPLE LEVELS OF SUCCESS 


\subsection{CONCLUSIONS}

\subsection{General Modelling Recommendations}

A strong general recommendation is that the modelling effort be tightly and continuously related to eventual function of the model. Specifically, as soon as a notional pass at any particular modelling effort has been achieved, it should be related to the decision process in which it is to be used to test the appropriateness of its specification. This will have the effect of testing whether the answers the model purports to yield leven if those answers are not yet believable because of the early stage in the modelling process) are effectively usable. It is often necessary to have trial results before a specification can be tested.

In addition, and at least as important, the appropriate directions for further modelling and/or data gathering can only be effectively determined by trial application. It is DDI's general position that the appropriate model depends crucially on exactly what options are to be compared. A general-purpose utility model, for example, is unlikely to be appropriate.

\subsection{1 "Top-down" modelling philosophy - Basically, two} contending modelling philosophies are available; we can choose between them or pursue them in parallel: "top down" and "bottom up."

The top-down approach says that one starts where one would like to end up--in this case a comparison of regulator options-and works progressively dowmard toward the detailed considerations. One starts with the coarsest, most comprehensive mode, in this case perhaps a direct 
assessment of the merits of the options under consideration. One then reviews the results of this stage before deciding whether and how to proceed to a more disaggregated level of modelling. In this case an informal look at the total argument might be followed by disaggregation into four directly assessed components of utility: societal risk, societal value, operator interest, and regulator interest.

Whereas the first stage involved directly comparing options on a single overall utility scale, noting the informal rationale underlying it, the second stage involves quantifying the components of utility, noting the rationale behind each evaluation and the importance weights between them.

The decision on where to make the next cut will be guided by which aspect of the current model appears most. critical. This is a function of where refined modelling is most likely to have an impact in terms of sensitivity of the final conclusion, and where there is most realistic scope for improvement. To some extent, one can anticipate without top-dow modeling where the direction for intensive modelling wili be, by informally considering the ultimate task to be performed, in which case one would be inclined to proceed from the "bottom up."

For example, if the choice is between performancebased as opposed to specification-based regulations, critical attention will need to be directed, informally or formally, to impact on regulator utility since this discriminates importantly between the two in terms of administrative convenience, judicial embarrassment, and so forth. Accordingly, one might want to devote a significant part of the resources to analyzing and modelling this dimension. On the other hand, if the choice were between numerical criteria inside a 
given format, say eight versus twenty-four hours for the detectability of significant diversions of plutonium, regulator utility would barely enter into this choice at all, compared with operator cost balanced against societal risk. Top-down modelling would then be unnecessary, at least. in terms of making the above more fine-grained modelling decisions.

\subsubsection{The "bottom-up" approach - Until recently, the} dominant modelling approach was to short-circuit the topdown cycling approach and make an immediate judgment as to the scale and direction of fine-grained modelling. This involves detailed modelling, of utility functions, uncertainty, and the like, whether in a comprehensive or partial analysis. The simultaneous development of ambitious nonlinear multi-attribute utility models, fault tree analysis, and adversary models would come under this category. This approach is predicated upon the judgment that its results will in fact contribute to the ultimate task, which may not be sharply specified in advance whether or not the exact mode of use has been formulated precisely in advance land it typically has not).

An advantage of this approach is that there is no delay in getting to the fine-grained modelling. Moreover, it is often clear (though less frequently than is imagined) that a given type of modelling is required. On the other hand, it carries with it the risk (often underestimated) that the balance of such detailed modelling effort will be mis-assigned or that when completed, it will not be responsive to the usage for which it was designed. A further advantage to the bottom-up approach is that it permits immediate, simultaneous specification of largely unrelated tasks, whoreas the top-down approach requires a high degree of incegration and a single source of control. 
A general preference is for the top-down approach. However, in situations where substantia! resources are to be applied across multiple task teams and over a short period of time, a recomnendation is to have one team (for example this subcontractor) assume a top-down approach and other teams, in parallel, Jursue different segments of the bottomup approach, e.g., response modeling, adversary modeliing, utility modelling, and so forth.

This procedure, which might be called "building the bridge from both ends," permits the higher order topdown model to be continually updated in the light of insights obtained from the lower order bottom-up model. Furthermore, in the opposite direction, the top-down activities may serve to prompt adaptive changes in the bottom-up work.

The above principle implies that the process of recycling the modelling activity is required. As rapidy as possible, the complete pass is made at model building and at use by the intended ultimate user bearing in mind, of course, the risk that the user may be discouraged by the primitive state of the modelling effort) in order to get feedback on whether the modelling effort is appropriately aimed and on what the best directions are for further effort. General experience indicates that no matter how carefully the research has been planned in advance, its direction is substantially modified based on the results of a first. pass.

\subsection{Further Work Proposed}

As discussed, one of the requirements for modelling effort is that it be continuously evaluated in terms of the model's eventual use. One aspect of such an evaluation is to ascertain whether the answers the model purports to yield 
are usable. Similarly, the eventual uses the model have significant implications for the implementation of the generalized model. One important step is, therefore, to interface with potential users of the model to determine the types of questions the model will be required to answer. As the actual regulation aid is developed, potential organizational constraints and requirements should be clearly kept in mind. It is only of intellectual interest to vary model parameters that cannot be varied in practice. Therefore, one direction for further work is to ascertain the interface between the model development and current NRC decision processes.

A second and different thrust for work is to investigate the cost of specific as opposed to generai levels of regulations. As earlier discussed, regulations can be in terms of overall societal utility, facility risk, probability thresholds, or in terms of highly specific technical characteristics such as the numbers, types, and locations of different sensors, Theoretically, the more general the regulations, the more freedom the facility designer has to trade off and therefore optimize the facility design from a cost/benefit point of view. As indicated, however, the more general the regulations, the harder they are to enforce. Similarly, the more specific the regulations, the easier they are to enforce, but theoretically they may be much less effective in terms of overall societal goals with respect to facilities. A basic quescion is, therefore, how much is saved in the regulation process by increasing the specificity of the regulations? At the same time, how much, if anything is lost in terms of the societal utility of the more general regulations that encourage design trade-offe. The general question here is, of course: What are the overall costs associated with differing levels of regulation generality? Work on this issue is fundamental to the evaluation of the regulation aid. 


\section{REFERENCES}

Barclay, S.; Brown, R. V.; Kelly, C. W. III; Peterson, C. R.; Phillips, I. D.; Selvidge, J. Handbook fcr Decision Analysis. Technical Report T $\overline{R-77-6-30 . ~}$ McLean, Virginia: Decisions and Designs, Incorporated, September 1977.

Brown, R. V. and Feuerwerger, P. H, A Macro-Model of Nuclear Safeguard Effectiveness, Interim Report PR 78-6-80. MeLean, Virginia: Decisions and Designs, Incorporated, March 1978.

U. S. Nuclear Regulatory Commission. Report of the Material Control and Material Safety and Safeguaras. Washington, D.C.: Office of Nuclear Material Safety and Safeguards, 1978. Volune II. 